\title{
Primary and secondary prophylaxis for Pneumocystis carinii related complications in HIV patients
}

\author{
M. Held*, F-D. Goebel**
}

At the beginning of the acquired immune deficiency syndrome (AIDS) era, nearly 15 yrs ago, Pneumocystis carinii pneumonia (PCP) was the most common human immunodeficiency virus (HIV)-related complication. PCP represented about $60 \%$ of the initial case-defining events of AIDS patients [1]. Almost $80 \%$ of HIV and AIDS patients experienced at least one episode of PCP in the course of their HIV infection [2,3]. Thanks to secondary prophylaxis, the number of relapses of PCP has recently declined. But PCP is still the most commonly reported AIDS-associated diagnosis amongst HIV-infected individuals in Western industrialized countries [4]. Mortality was high, as the disease was not recognized early enough in many cases and the benefits of systemic steroids were not known at that point of time $[5,6]$.

Increased risks for PCP are: a CD4+ count $<200$ cells $\mu \mathrm{L}^{-1}$ at the time of AIDS diagnosis; male homosexuality/bisexuality; and the diagnosis of AIDS in northern Europe [7]. Of AIDS patients with a history of one or more episodes of PCP, $60 \%$ are likely to experience another relapse within one year if specific prophylaxis is not administered $[8,9]$. A recent study suggested that some recurrent episodes of PCP are caused by reinfection rather than by reactivation of latent infection. This hypothesis is based on genetic heterogeneity of mitochondrial ribosomal ribonucleic acid (RNA) gene of Pneumocystis carinii hominis isolates from AIDS patients with recurrent episodes of PCP [10].

In 1990, LeOung et al. [9] published the first report proving the prophylactic efficacy of inhaled aerosolized pentamidine against PCP in 408 high-risk HIV patients. A dose of $300 \mathrm{mg}$ aerosolized pentamidine administered once monthly by jet nebulizer was the most effective secondary prophylaxis. After 18 months, only 8 out of 139 participants receiving the $300 \mathrm{mg}$ schedule had experienced a PCP relapse, as compared with 22 out of 135 subjects having been randomized to receive the low dose of $30 \mathrm{mg}$ pentamidine every 2 weeks [9]. Another study investigated the preventive value of inhaled pentamidine in $223 \mathrm{HIV}$ patients $\left(<200 \mathrm{CD} 4+\right.$ cells $\left.\cdot \mu \mathrm{L}^{-1}\right)$ or AIDS related complex $=$ Centers for Disease Control $(\mathrm{CDC})$ B3 in the current classification) without previous episode of PCP. Eight patients with primary prophylaxis versus 23 patients in the placebo group experienced a PCP $(\mathrm{p}=0.0021)$ [11].

On the basis of these two studies, the regular application of aerosolized pentamidine for primary and secondary

*Ruhrlandklinik, Dept of Pneumology and Allergy, University Essen, Tüschener Weg 40, 45239 Essen, Germany. **Med. Poliklinik of University Munich, Pettenkoferstraße 8a, 80336 München, Germany. prophylaxis against PCP had become a standard of management in HIV patients with less than $200 \mathrm{CD} 4+$ cells $\mu \mathrm{L}^{-1}$ or in AIDS patients with a previous episode of PCP.

Administration of pentamidine by jet nebulizer and by ultrasonic nebulizer provides sufficient respirable particles [12]. Adverse events are rare and limited to transient unpleasant taste and cough. Smokers or patients with bronchial hyperreactivity may develop bronchospasm, which is usually prevented by prior administration of two puffs of a bronchodilator [13]. Long-term, unwanted effects or irreversible ventilatory dysfunctions are not known in patients regularly inhaling aerosolized pentamidine [14, 15]. Rash [16], pancreatitis [17], hypoglycaemia [17], diabetes [18], and renal insufficiency [19] have been described but occur much more commonly when pentamidine is administered intravenously. The association between the application of aerosolized pentamidine and the development of spontaneous pneumothorax is well-known [20]. Also, the financial aspects of aerosolized pentamidine cannot be overlooked; this prophylaxis being about five times more expensive than the administration of co-trimoxazole and about 10 times as expensive as dapsone.

Additionally, there have been several reports describing extrapulmonary manifestations of Pneumocystis carinii. These are found in $0.5-3 \%$ of patients with PCP [21]. About 50\% occur in HIV patients, despite regular inhalation of aerosolized pentamidine. Positive blood polymerase chain reactions (PCRs) for Pneumocystis carinii indicate haematogenous spread during acute pneumonia [22]. Almost all organs can be involved in disseminated Pneumocystis carinii infections in AIDS. Examples are mastoiditis [23], skin manifestations [24], hepatitis [25], splenitis [26], thyroiditis or the involvement of the bone marrow [27] with secondary pancytopenia.

In this issue of the Journal, EwIG et al. [28] report an incidence of breakthrough PCP of $23 \%$ at 36 months in 95 HIV-infected patients with primary aerosolized pentamidine prophylaxis, similar to results published previously [29]. EwIG et al. [28] compared the clinical and radiographic presentation as well as the outcome of breakthrough PCP in those patients with "early" ( $\leq 12$ months of inhalation time) and with "late" (>12 months of inhalation time) failure, and found no difference between these two groups. Presentation with upper lobe infections was also a radiographic pattern of late failures. EDELSTEIN and MCCABE [30] first described this atypical presentation in 1990 and, in contrast to EwIG et al. [28], they observed complicated courses, such as cavities and pneumothoraces. Lung cavitation in PCP may also occur without inhaled pentamidine prophylaxis [31]. 
One limitation of the report by EwIG et al. [28] is the small number of breakthrough PCP, which makes the statistical comparison of the two populations doubtful (six cases of "early" failure versus 14 cases of "late" failure). Like others before, EwIG et al. [28] advise the sitedirected lavage technique [32]. This recommendation is particularly important to enhance the diagnostic sensitivity in cases of PCP with atypical clinical and/or radiographic presentation. Some clinicians recommend that aerosolized pentamidine should be inhaled in different positions (sitting as well as lying), believing that this ensures better contact of the upper pulmonary lobes with the aerosol. No published data are available to confirm the efficacy of this procedure. It is important to note that systemic prophylaxis with trimethoprim-sulphamethoxazole (TMP-SMX) is also associated with upper lobe recurrence of PCP [33].

The limitations of an effective prophylaxis against systemic pneumocystosis with inhaled pentamidine and the incomplete protection for patients with a history of prior PCP have been important reasons to search for alternative prophylactic regimens.

The introduction of orally administered TMP-SMX solved some of the problems discussed above. TMPSMX is inexpensive, can be administered orally and provides a systemic distribution of the agent. The first controlled trial comparing the efficacy of TMP-SMX with aerosolized pentamidine in secondary prophylaxis of PCP in 310 AIDS patients showed that TMP-SMX is superior to aerosolized pentamidine with respect to the recurrences of PCP (14 versus 36 relapses; $\mathrm{p}<0.001$ ) [34]. Moreover, bacterial infections and cerebral toxoplasmosis occurred less often during therapy with TMP-SMX. Similar results were obtained in a trial for primary prophylaxis [35]. Consequently, in 1992 the US Public Health Service recommended TMP-SMX as first-line prophylaxis for all HIV-infected patients at high risk for acquiring PCP [36]. Different regimens were tested to define the minimal dose of TMP-SMX necessary to prevent PCP and toxoplasmosis. Trimethoprim, $160 \mathrm{mg}$, and sulphamethoxazole, $800 \mathrm{mg}$, (= one double-strength tablet three times a week [37], or two double-strength tablets two times a week [38]) yield comparable satisfying results.

Dapsone is another promising antifolate drug for Pneumocystis carinii and Toxoplasma gondii prophylaxis. Oral dapsone, $100 \mathrm{mg}$, has been shown to be as effective as the daily intake of one double-strength tablet of TMP-SMX in primary PCP prophylaxis [39]. However, dapsone is associated with haemolytic anaemia and methaemoglobinaemia in rare cases. A recent study compared the oral administration of $200 \mathrm{mg}$ dapsone together with $75 \mathrm{mg}$ pyrimethamine once a week with aerosolized pentamidine. The randomized, open trial demonstrated a longer survival time in the pentamidine group [40]. However dapsone/pyrimethamine more effectively prevented infections with Pneumocystis carinii and Toxoplasma gondii than aerosolized pentamidine [41]. Moreover, a subanalysis of the results of this study reveals a slight, nonsignificant trend indicating that this regimen may provide an additional prophylactic effect against atypical mycobacterial infections [42].

A number of studies in 1993 have already suggested the superior effect of dapsone/pyrimethamine over aerosolized pentamidine for the simultaneous prevention of cerebral toxoplasmosis. These studies have shown an at least equal effect of dapsone/pyrimethamine on primary PCP prophylaxis compared with aerosolized pentamidine [43, 44]. PODZAMCZER et al. [45] demonstrated that thrice weekly TMP-SMX was even more effective than weekly dapsone-pyrimethamine for the primary prevention of PCP in HIV-infected patients. In contrast, a large study $(n=843)$ published in 1995 showed a similar efficacy of TMPSMX and dapsone, with an estimated 36 month cumulative risk of 19 versus $22 \%$, respectively [28]. Both were superior to aerosolized pentamidine (33\% risk), especially in HIV patients with less than $100 \mathrm{CD} 4+$ cells $\cdot \mu \mathrm{L}^{-1}$. The investigation consisted of three arms: TMP-SMX (one double-strength tablet b.i.d.) versus dapsone (100 $\mathrm{mg}$ q.d. orally) versus aerosolized pentamidine (300 $\mathrm{mg}$ every 4 weeks, administered by a Respigard II nebulizer). The median survival was approximately equal in all three groups and not related to new episodes of PCP [28].

In summary, many studies and a bulk of data exist dealing with the question of optimal primary and secondary prophylaxis against $\mathrm{PCP} /$ toxoplasmosis. As the investigators used different dosages of the same agent, enrolled differently immunocompromised populations of HIV patients, and investigated primary and secondary prophylaxis, it is difficult to obtain a clear picture of the optimal prophylactic regimen. In general, there are advantages of orally given drugs over aerosolized pentamidine, and TMP-SMX seems to be slightly superior to dapsone/pyrimethamine. However, aerosolized pentamidine remains an important reserve drug for PCP prophylaxis because some HIV patients are intolerant of antifolate agents and develop allergic reactions [34]. The simultaneous intake of folinic acid does not improve the tolerance to TMP-SMX whether zidovudine is additionally administered or not [46]. The consequent application of secondary PCP prophylaxis and the recent introduction of antiretroviral agents have increased the 1 and 2 year survival rates after the diagnosis of PCP.

However, 3 year survival has remained unchanged over time, implying that the underlying immunodeficiency and related infectious and malignant complications are not under control [47].

In conclusion, trimethoprim-sulphamethoxazole appears to be the treatment of choice for primary and secondary Pneumocystis carinii pneumonia prophylaxis. However, there is an urgent need for the development of new, better drugs with a wider range of protection against the various opportunistic infections.

\section{References}

1. Centers for Disease Control. Update: acquired immunodeficiency syndrome - United States. 1986; 35: 757-766.

2. Centers for Disease Control. Update: acquired immunodeficiency syndrome - United States 1986; 35: 17-21.

3. Allegra CJ, Chabner BA, Tuazon CU, et al. Trimetrexate for the treatment of Pneumocystis carinii pneumonia in patients with acquired immunodeficiency syndrome. $N$ Engl J Med 1987; 317: 978-985.

4. Munoz A, Schrager LK, Bacellar H, et al. Trends in the incidence of outcomes defining acquired immunodeficiency syndrome (AIDS) in the multicenter AIDS cohort study: 1985-1991. Am J Epidemiol 1993; 137: 423-438. 
5. Gagnon S, Boota AM, Fischl MA, et al. Corticosteroids as adjunctive therapy for severe Pneumocystis carinii pneumonia in the acquired immunodeficiency syndrome: a double-blind, placebo-controlled trial. $N$ Engl J Med 1990; 323; 1444-1450.

6. Nielsen TL, Eeftinck-Schattenkerk JK, Jensen BN, et al. Adjunctive corticosteroid therapy for Pneumocystis carinii pneumonia in AIDS: a randomized European multicenter open label study. J Acquir Immune Defic Syndr 1992; 5: 726-731.

7. Lundgren JD, Barton SE, Lazzarin A, et al. Factors associated with the development of Pneumocystis carinii pneumonia in 5,025 European patients with AIDS. Clin Infect Dis 1995; 21: 106-113.

8. Fischl MA, Parker CB, Pettinelli C, et al. and the AIDS Clinical Trials Group. A randomized controlled trial of reduced daily dose of zidovudine in patients with the acquired immunodeficiency syndrome. $N \mathrm{Engl} \mathrm{J} \mathrm{Med}$ 1990; 323: 1010-1025.

9. Leoung GS, Feigal DW, Montgomery AB, et al. and the San Francisco County Community Consortium. Aerosolized pentamidine for prophylaxis against Pneumocystis carinii: the San Francisco Community Prophylaxis Trial. N Engl J Med 1990; 323: 769-775.

10. Keely SP, Stringer JR, Baughman RP, et al. Genetic variation among Pneumocystis carinii hominis isolates in recurrent pneumocystosis. J Infect Dis 1995; 172: 595-598.

11. Hirschel B, Lazzarin A, Chopard P, et al. and the Swiss Group for Clinical Studies in AIDS. A controlled study of inhaled pentamidine for primary prevention of Pneumocystis carinii pneumonia. N Engl J Med 1991; 324: 10791083.

12. Ilowite JS, Baskin MI, Sheetz MS, Abd AG. Delivered dose and regional distribution of aerosolized pentamidine using different delivery systems. Chest 1991; 99: 1139-1144.

13. Quiffin J, Hunter J, Schechter MT, et al. Aerosol pentamidine-induced bronchoconstriction: predictive factors of therapy. Chest 1991; 100: 624-627.

14. Camus F, de Picciotto C, Lepretre A, et al. Pulmonary tolerance of prophylactic aerosolized pentamidine in human immunodeficiency virus-infected patients. Chest 1991; 99: 609-612.

15. Tullis E, Yu DG, Rawji A, et al. The long-term effects of aerosol pentamidine on pulmonary function. Clin Invest Med 1992; 15: 42-48.

16. Berger TG, Tappero JW, Leoung GS, et al. Aerosolized pentamidine and cutaneous eruptions. Ann Intern Med 1989; 110: 1035-1036.

17. Murphy RL, Lavelle JP, Allan JD, et al. Aerosolized pentamidine prophylaxis following Pneumocystis carinii pneumonia in AIDS patients: results of a blinded dosecomparison study using an ultrasonic nebulizer. Am J Med 1991; 90: 418-426.

18. Chen JP, Braham RL, Squires KE. Diabetes after aerosolized pentamidine. Ann Intern Med 1991; 114: 913-914.

19. Chapelon C, Raguin G, De Gennes C. Renal insufficiency with nebulized pentamidine. Lancet 1989; 8670: 1045-1046.

20. Newsome GS, Ward DJ, Pierce PF. Spontaneous pneumothorax in patients with acquired immunodeficiency syndrome treated with prophylactic aerosolized pentamidine. Arch Intern Med 1990; 150: 2167-2168.

21. Raviglione MC. Extrapulmonary pneumocystosis: the first 50 cases. Rev Infect Dis 1990; 12: 1127-1138.

22. Schluger N, Sepkowitz K, Armstrong D, et al. Detection of Pneumocystis carinii in serum of AIDS patients with
Pneumocystis carinii pneumonia by polymerase chain reaction. Forty fourth Annual Meeting of the Society of Protozoologists, Bozeman, Montana, 1991.

23. Gherman CR, Ward RR, Bassis ML. Pneumocystis carinii otitis media and mastoiditis as the initial manifestation of the acquired immunodeficiency syndrome. Am J Med 1988; 85: 250-252.

24. Hennessy NP, Parro EL, Cockerell CJ. Cutaneous Pneumocystis carinii infections in patients with acquired immunodeficiency syndrome. Arch Dermatol 1991; 127: 1699-1701.

25. Poblete RB, Rodriquez K, Foust RT, et al. Pneumocystis carinii hepatitis in the acquired immunodeficiency syndrome (AIDS). Ann Intern Med 1989; 110: 737-740.

26. Unger PD, Rosenblum M, Krown SE. Disseminated Pneumocystis carinii infection in a patient with acquired immunodeficiency syndrome. Hum Pathol 1988; 19: 113-116.

27. Momose H, Lee S. Pneumocystis carinii as foamy exudate in bone marrow. JAMA 1991; 265: 1672.

28. Ewig S, Schäfer H, Rockstroh JK, et al. Effect of longterm primary aerosolized pentamidine prophylaxis on breakthrough Pneumocystis carinii pneumonia. Eur Respir J 1996; 9: 1006-1012.

29. Bozzette SA, Finkelstein DM, Spector SA, et al. A randomized trial of three antipneumocystis agents in patients with advanced human immunodeficiency virus infection. N Engl J Med 1995; 332: 693-699.

30. Edelstein H, McCabe RE. Atypical presentations of Pneumocystis carinii pneumonia in patients receiving inhaled pentamidine prophylaxis. Chest 1990; 98: 1366-1369.

31. Ferre C, Baguena F, Podzamczer D, et al. Lung cavitation associated with Pneumocystis carinii infection in the acquired immunodeficiency syndrome: a report of six cases and review of the literature. Eur Respir J 1994; 7: 134-139.

32. Baughman RP, Dohn MN, Shipley R, et al. Increased Pneumocystis carinii recovery from the upper lobes in Pneumocystis pneumonia: the effect of aerosol pentamidine prophylaxis. Chest 1993; 103: 426-432.

33. Quinn JW, Baumgart KW, Garsia RJ. Pneumocystis carinii pneumonia: upper lobe recurrence following cotrimoxazole. Aust NZ J Med 1991; 21: 380-381.

34. Hardy DW, Feinberg J, Finkelstein DM, et al. for the AIDS Clinical Trials Group. A controlled trial of trimethoprim-sulfamethoxazole or aerosolized pentamidine for secondary prophylaxis of Pneumocystis carinii pneumonia in patients with the acquired immunodeficiency syndrome. AIDS Clinical Trials Group Protocol 021. N Engl J Med 1992; 327: 1842-1848.

35. Schneider ME, Hopelman AIM, Eeftinck Schattenkerk JKM, et al. and the Dutch AIDS Treatment Group. A controlled trial of aerosolized pentamidine or trimethoprim-sulfamethoxazole as primary prophylaxis against Pneumocystis carinii pneumonia in patients with human immunodeficiency virus infection. N Engl J Med 1992; 327: 1836-1841.

36. Recommendations for prophylaxis against Pneumocystis carinii pneumonia for adults and adolescents infected with HIV. MMWR 1992; 41 (No.RR-4): 1-12.

37. Ruskin J, La Riviere M. Low-dose co-trimoxazole for prevention of Pneumocystis carinii pneumonia in human immunodeficiency virus disease. Lancet 1991; 337: 468-471.

38. Carr A, Tindall B, Brew BJ, et al. Low dose trimethoprim-sulfamethoxazole prophylaxis for toxoplasmic encephalitis in patients with AIDS. Ann Intern Med 1992; 117: 106-111. 
39. Blum RN, Miller LA, Gaggini LC, et al. Comparative trial of dapsone versus trimethoprim/sulfamethoxazole for primary prophylaxis of Pneumocystis carinii pneumonia. J Acquir Immune Defic Syndr 1992; 5: 341346.

40. Salmon-Ceron D, Fontbonne A, Saba J, et al. Lower survival in AIDS patients receiving dapsone compared with aerosolized pentamidine for secondary prophylaxis of Pneumocystis carinii pneumonia. J Infect Dis 1995; 172: 656-664

41. Opravil M, Hirschel B, Lazzarin A, et al. Once-weekly administration of dapsone/pyrimethamine $v s$ aerosolized pentamidine as combined prophylaxis for PC pneumonia and toxoplasmic encephalitis in HIV-infected patients. Clin Infect Dis 1995; 20: 531-541.

42. Opravil M, Pechere M, Lazzarin A, et al. Dapson/ pyrimethamine may prevent mycobacterial disease in immunosuppressed patients infected with the human immunodeficiency virus. Clin Infect Dis 1995; 20: 244-249.

43. Torres RA, Barr M, Thorn M, et al. Randomized trial of dapsone and aerosolized pentamidine for the prophylaxis of Pneumocystis carinii pneumonia and toxoplasmic encephalitis. Am J Med 1993; 95: 573-583.

44. Girard P-M, Landman R, Gaudebout C, et al. Dapsonepyrimethamine compared with aerosolized pentamidine as primary prophylaxis against Pneumocystis carinii pneumonia and toxoplasmosis in HIV infection. $N$ Engl $J$ Med 1993; 328: 1514-1520.

45. Podzamczer D, Santin M, Jimenez J, et al. Thrice weekly co-trimoxazole is better than weekly dapsone-pyrimethamine for the primary prevention of Pneumocystis carinii pneumonia in HIV-infected patients, AIDS 1993; 7: 501506.

46. Bozzette SA, Forthal D, Sattler FR, et al. The tolerance for zidovudine plus thrice weekly or daily trimethoprimsulfamethoxazole with and without leukovorin for primary prophylaxis in advanced HIV disease. Am J Med 1995; 98: 177-182.

47. Lundgren JD, Barton SE, Katlama C, et al. Changes in survival over time after first episode of Pneumocystis carinii pneumonia for European patients with acquired immunodeficiency syndrome. Arch Intern Med 1995; 155: 822-828. 